\title{
ANTROPOCENO \\ E A TRANSICIÓN URBANA
}

José María Tubío Sánchez

Eduardo Corbelle Rico

Francisco Ónega López

IBADER. Laboratorio do Territorio

Campus de Lugo (USC) 



\section{A TRANSICIÓN URBANA. UN FENÓMENO GLOBAL}

Os efectos da acción do ser humano no sistema Terra están sendo cada vez máis visibles. Un dos principais resultados desta acción é o que se adoita denominar co concepto de transición urbana. Este é un termo sobre todo demográfico que fai referencia á perda de poboación das áreas rurais en favor das urbanas. Este proceso veuse acelerado nas últimas décadas. En 1950 máis de dous terzos (70 \%) das persoas vivían en asentamentos rurais e menos dun terzo (30\%) en asentamentos urbanos. En 2017, arredor do $55 \%$ da poboación mundial é urbana. Segundo as Nacións Unidas (2014), a poboación urbana continuará crecendo de xeito que, para o 2050, as porcentaxes de poboación rural e urbana serán de $34 \%$ e $66 \%$ respectivamente, aproximadamente o reverso das porcentaxes de 1950. Un dato que xa é icónico é o de 2007, cando a poboación urbana superou por primeira vez á poboación rural na historia da humanidade. En todo caso, estas cifras son moi cuestionables debido á dificultade estatística de medir, incluso diacronicamente, a poboación urbana e rural. Algúns autores suxiren que a transición urbana é un artefacto estatístico sen base, e o propio concepto, un termo caótico (Brenner e Schmitd 2014).

A miúdo o propio concepto de transición urbana confúndese con algunhas das consecuencias que pode levar consigo un cambio que si é estrutural e global en canto ao uso da terra. Neste sentido, a transición urbana pode tomar diferentes formas ou camiños, que resultan moi parecidos en termos demográficos con relación á porcentaxe de poboación rural e urbana pero moi diferentes con relación ao impacto territorial. Por exemplo, a transición urbana entendida como transición demográfica pode estar asociada ou non á perda da superficie agrícola, os procesos urbanizadores poden ser máis ou menos intensos respecto ás 
necesidades habitacionais dunha sociedade ou o patrón de crecemento urbano pode ser máis ou menos compacto e consumir máis ou menos recursos naturais. Aínda que todos os países do mundo sufriron, sobre todo desde os anos cincuenta, unha transición urbana de forma acelerada, os resultados desta transición están deixando en cada país resultados moi diferentes. O interesante non é medir a propia transición, senón entender os efectos que están causando no territorio e as razóns que hai detrás. O obxectivo deste traballo é polo tanto reflexionar sobre cales son as forzas que están detrás desta transición urbana, cuantificar cal é o impacto da transición urbana en Galicia en relación co consumo do recurso terra e, finalmente, entender que micro-dinámicas están agravando en Galicia os efectos desta transición.

\section{AS ORIXES DA TRANSICIÓN URBANA}

Aínda sendo un fenómeno complexo, a transición urbana pódese considerar o resultado do éxito con relación á capacidade de control dos recursos naturais por parte do ser humano. As orixes da transición urbana teñen lugar no que se denominou a segunda revolución agrícola, que aconteceu en Inglaterra durante os séculos XVII-XVIII. A mellora das condicións sanitarias favoreceu un incremento da poboación que era necesario alimentar. O progreso da agricultura (novas técnicas, cercados etc.) permitiu intensificar a produción e que os propietarios da terra recibisen unha renda polo comercio dos produtos agrícolas. É importante salientar que o crecemento de poboación urbana vai parello a unha intensificación progresiva da agricultura. A expansión dos usos das enerxías fósiles, dun xeito gratuíto, impulsada sobre todo despois da Revolución Industrial, vai acelerar estas tendencias. Os traballos do economista David Ricardo propoñen un modelo de renda da terra para explicar as transformacións na propiedade e a xestión da Inglaterra neses anos. Este modelo, como todos os que tratan de explicar a renda da terra, tamén é no fondo un modelo demográfico. 
A partir de 1950 a poboación mundial acelera o seu ritmo de crecemento e dobrouse en apenas 50 anos. Isto levará a que se complete un traslado masivo de poboación campesiña, sobre todo en América Latina, cara á cidade. Ademais, as áreas metropolitanas comezarán a medrar a través dun crecemento endóxeno cada vez máis acelerado. En EE. UU. e Europa completarase esa transformación que se iniciara moitos anos antes. As innovacións tecnolóxicas así como as melloras no transporte van permitir que a terra urbana sexa ao mesmo tempo xeradora de rendas debido ao efecto das economías de aglomeración (Fujita / Venables / Krugman, 1999), así como un sumidoiro do excedente de capital (Stiglitz, 2015), que termina con frecuencia en burbullas inmobiliarias. O modelo de rendas de terras urbanas de Alonso (1964), que se basea na renda ofertada pola terra, describe non soamente como se forma a renda nas áreas urbanas actualmente, senón que, igual que o precursor Ricardo, describe tamén un modelo demográfico.

No contexto da transición urbana a partir de 1950, a superficie agrícola que subministra alimentos á humanidade mantense máis ou menos estable desde eses anos ata a actualidade. A produtividade agrícola dóbrase mediante unha intensificación nunca vista ata o de agora, para atender as necesidades alimentarias do dobre de poboación (Dubois 2011). As áreas urbanas, aínda sendo unha pequena porcentaxe da superficie da terra dispoñible, van gañando cada vez máis repercusión económica e hoxe en día concentran o 70 \% do PIB mundial.

\section{SOBREURBANIZACIÓN}

Como diciamos anteriormente, as consecuencias da transición urbana poden ter diferentes impactos. Un deles é a sobreurbanización. Nos anos 50 converteuse nun termo bastante popular na literatura académica, sobre todo aplicado a países en vías de desenvolvemento. O vocábulo indica que a velocidade coa que se urbanizan os países excede a velocidade coa que se industrializan. Aínda que o 
concepto se esvaeceu do discurso académico despois das críticas de Sovani (1964) debido á súa vaguidade e imprecisión, pode resultar interesante se se redefine noutros termos. Neste traballo denominamos sobreurbanización o exceso de terra urbana dispoñible para as necesidades habitacionais dunha determinada poboación. Deste xeito, centrarémonos nunha das consecuencias frecuentes da transición urbana á que a miúdo non se lle presta suficiente atención.

En canto ao consumo de recursos, en particular o recurso terra, a superficie urbana (estea edificada ou teña dereitos de edificación) pode ser útil para entender comparativamente de canta terra se dispón para habitar. O aumento da superficie urbana per cápita é un fenómeno global (Seto et al. 2011). No caso europeo, o aumento nas áreas de morfoloxía urbana medrou un $146 \%$ entre 1990 e 2006 (Triantakonstantis / Stathakis 2015), mentres que a poboación só o fixo un $5 \%$ no mesmo período. Polo tanto, parece que cada vez usamos máis terra para cubrir as nosas necesidades habitacionais. Ademais, o patrón das áreas urbanas deixou de ser compacto e volveuse cada vez máis disperso (Environmental European Agency 2016).

No caso español, se consideramos a superficie tanto urbana como urbanizable per cápita dos municipios que aglutinan o $80 \%$ da poboación, vemos que existen diferenzas considerables por comunidade autónoma (vid. mapa 1). O Levante español ten unha menor superficie urbana por persoa que o noroeste. Estas desigualdades son consecuencia, sobre todo, do declive demográfico que está a experimentar o noroeste, onde boa parte dos municipios van perdendo poboación pero non por iso os plans reducen a superficie urbana que clasifican.

\section{O CASO GALEGO}

Segundo os datos do Sistema de Información de Ordenación do Territorio e Urbanismo de Galicia (SIOTUGA) da Consellería de Medio Ambiente, dispoñibles para 272 dos 314 municipios, os plans urbanísticos vixentes actualmen- 
Mapa 1. Superficie con dereitos de edificación (en ha) por persoa

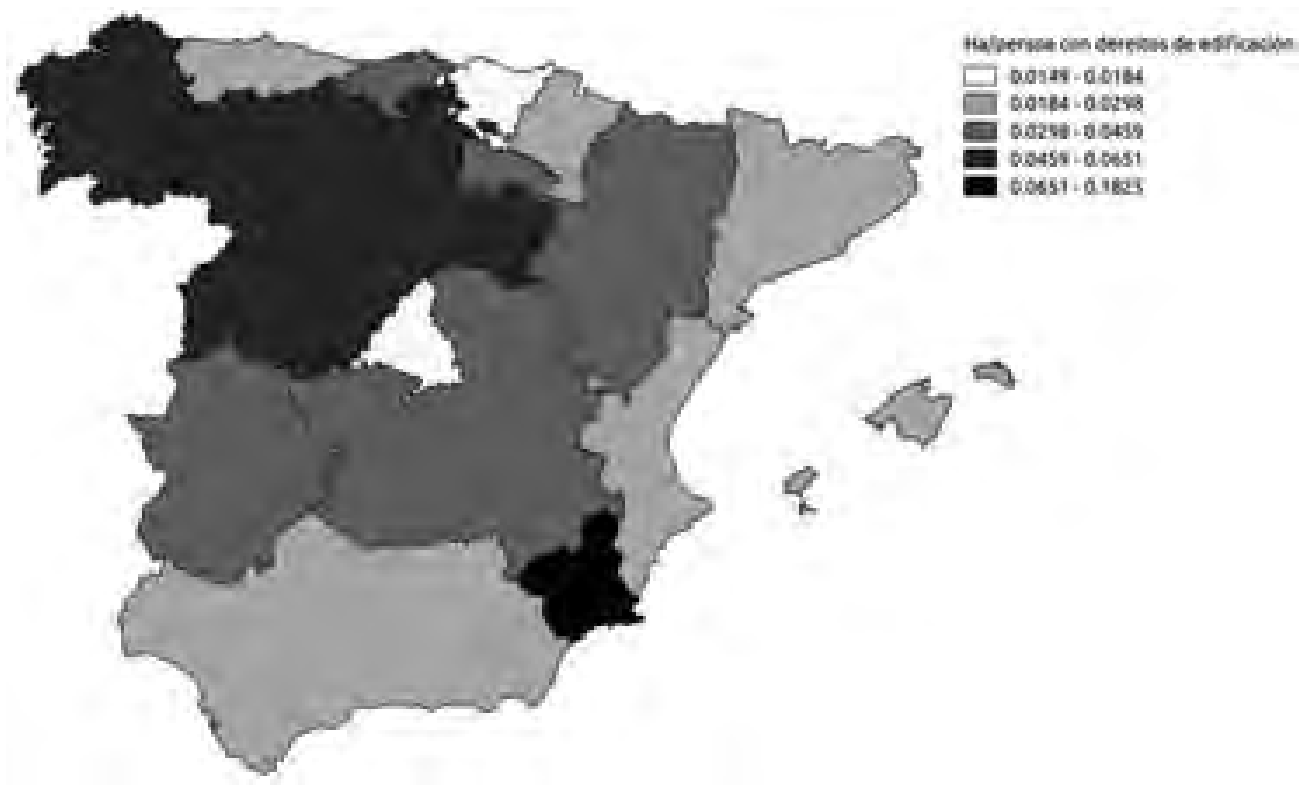

te en Galicia clasifican un total 206009 ha (vid. mapa 2) de solo con algún tipo de dereito de edificación. Esta superficie de solo con dereitos de edificación divídese en tres grandes clases: solo urbano, solo urbanizable e núcleo rural. Das máis de 200000 ha de solos clasificados con dereitos de edificación, un $24 \%$ (50 433 ha) pertence á clase urbanística solo urbano. A clase de solo urbanizable representa un 28 \% (58 292 ha) do total de solo con dereitos de edificación. Especial atención merece a categoría de solo de núcleo rural. Esta representa arredor da metade de solo con dereitos de edificación e aproxímase ás 100000 ha. A categoría de solo de núcleo rural faise relevante pola súa dimensión, que vai máis aló dunha solución singular que dá resposta ao patrón de dispersión de asentamentos en Galicia para converterse nun instrumento que explica as dinámicas urbanas, de escala territorial, observadas en Galicia nas últimas catro décadas. 
Mapa 2. Superficie con dereitos de edificación

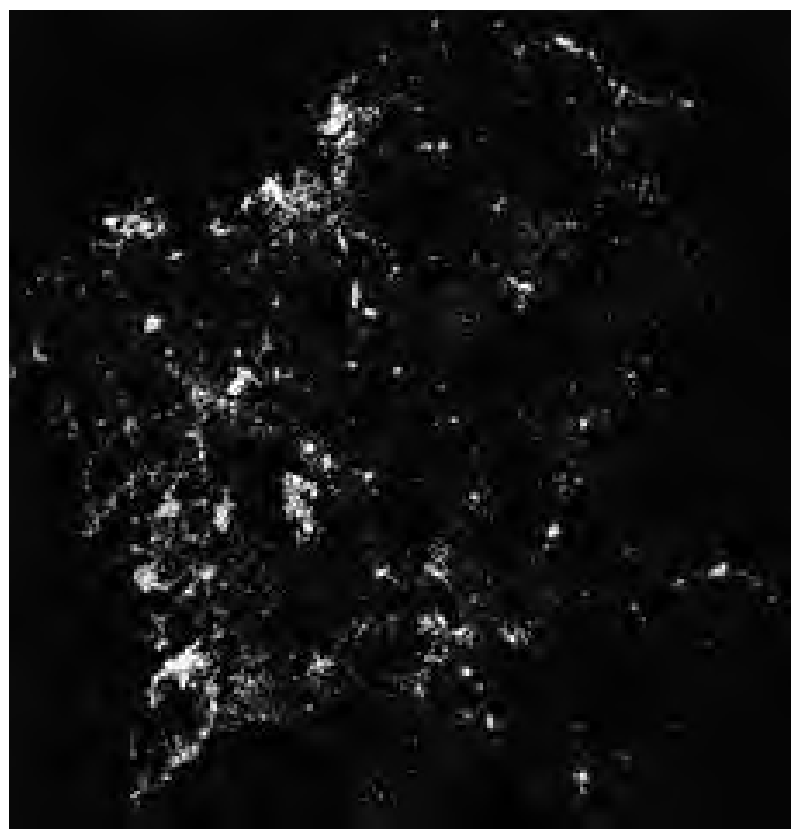

Boa parte do solo urbano (tanto o edificado como o que ten dereitos de edificación) atópase nos mellores solos de Galicia. Segundo o mapa da capacidade produtiva dos solos de Galicia de Díaz-Fierros e Gil Sotres (1984), que clasifica a terra en sete clases de acordo coa calidade produtiva do solo, Galicia conta con moi pouca superficie das mellores clases (ao redor dun $7 \%$ da clase A e un $13 \%$ da clase B). Non obstante, a superficie urbana nesas clases é dun 16 e un 16,7 \% respectivamente. No gráfico 1 compárase a porcentaxe das sete clases de solo coa porcentaxe de urbanización destes. Hai dous feitos que cómpre salientar segundo este gráfico. O primeiro é que a clase de núcleo rural é a predominante en canto á superficie en todas as clases de solo de Díaz-Fierros e Gil Sotres. Por outra parte, obsérvase que a proporción de solo urbano é maior canto mellor é a clase do solo. Non parece, polo tanto, que as diferentes leis do solo que se aprobaron en Galicia fosen capaces dunha protección eficaz deste tipo de terras, a pesar dos seus valores produtivos e ambientais. 
Gráfico 1: Clases de solo urbano e clases de solo segundo a aptitude agrícola (A-maior, G-menor)

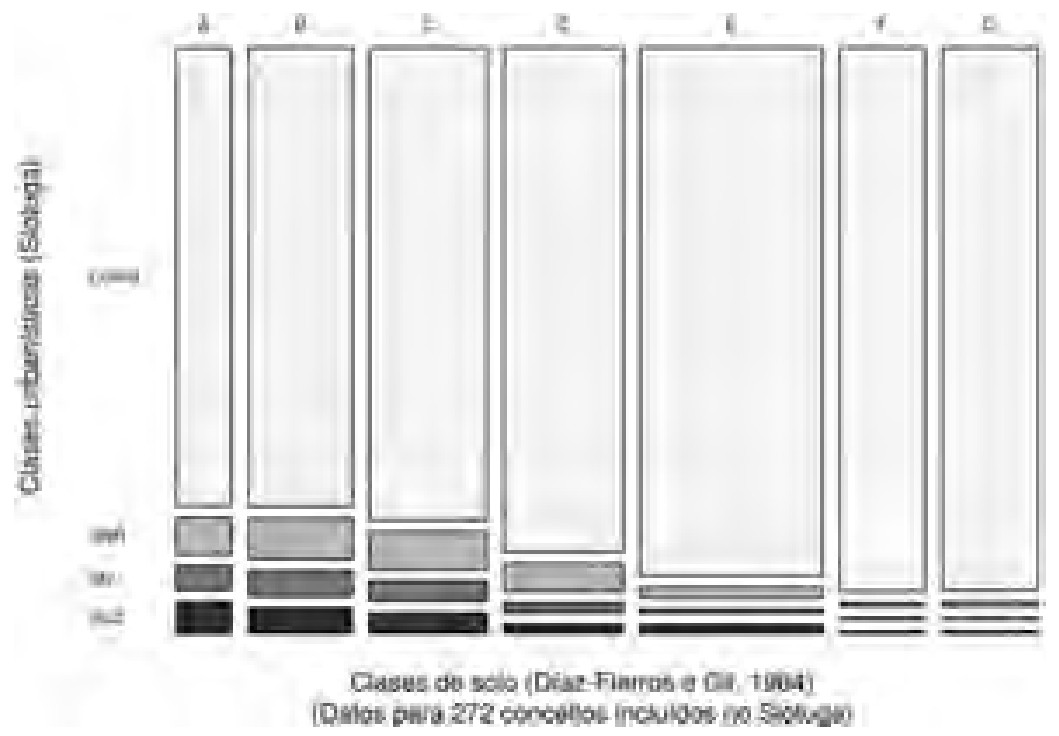

Táboa 1. Clases de solos urbanos (en \%) por clase de solo segundo Díaz-Fierros e Gil-Sotres (1984)

\begin{tabular}{lccccccc}
\hline & A & B & C & D & E & F & G \\
\hline SNR & 6,70 & 7,46 & 6,92 & 5,04 & 1,85 & 0,61 & 0,83 \\
\hline SU & 4,45 & 4,61 & 3,60 & 1,74 & 0,68 & 0,20 & 0,18 \\
\hline SUZ & 5,75 & 4,66 & 3,73 & 1,67 & 1,57 & 0,43 & 0,44 \\
\hline Outros & 83,09 & 83,27 & 85,75 & 91,56 & 95,90 & 98,76 & 98,55 \\
\hline
\end{tabular}

$\mathrm{SNR}=$ solo de núcleo rural, $\mathrm{SU}=$ solo urbano, $\mathrm{SUZ}=$ solo urbanizable.

\section{DISCUSIÓN}

A transición urbana en Galicia tivo como consecuencia a perda de poboación nas áreas rurais en favor das urbanas. Aínda que isto non acaba por explicar o 
patrón urbanizador que tivo lugar en Galicia, en especial durante os últimos 40 anos. $\mathrm{O}$ mesmo cambio demográfico podería ser realizado utilizando unhas 60000 ha de terra, que é aproximadamente a superficie urbana coa que conta Galicia actualmente, se esta estivese consolidada e contase cos núcleos rurais tradicionais compactos. Porén, os municipios galegos clasificaron a través da clase de núcleo rural e solo urbanizable unhas 160000 ha máis. Para poñermos estas cifras en contexto, esta superficie é a metade que utiliza o gando vacún de leite. Non parece factible, coa dinámica demográfica actual, que Galicia necesite toda esa superficie de terra urbanizable, que multiplica case por tres o solo urbano actual.

A pesar das diferentes regulacións e as leis do solo que indican que o desenvolvemento urbano ten que ser racional, parece que nin os municipios nin a Secretaría Xeral de Urbanismo, que é o órgano competente que tutela os concellos para que os plans cumpran coa lei, tivesen moi en conta os obxectivos colectivos con relación á terra urbana. Por que sucede isto?

As razóns que demos arriba para explicar a transición urbana pódense afiar un pouco máis cando intentamos entender o caso galego. A nivel global, os gobernos locais pasaron nos anos 70 de tomar decisións desde unha perspectiva de xestión dos asuntos públicos locais a unha máis empresarial (Harvey 1989). Isto débese en parte a que os gobernos locais tiñan cada vez máis competencias e menos recursos. No caso español, por mor do ingreso de España na UE e os correspondentes límites en relación co endebedamento das facendas locais, os municipios víronse na obriga de buscar fontes alternativas de financiamento. Dada a capacidade de xeración de renda das terras urbanas, xa comentada arriba, os gobernos locais atoparon no desenvolvemento urbano un instrumento de financiamento (Cabasés Hita 2011). En xeral, a nivel español, os municipios fixéronse máis dependentes da actividade urbanística para sanear as súas finanzas (Sánchez Maldonado / Suárez Pandiello 2007; Baza Román / Gobernado Rebaque 2016). O planeamento urbanístico convértese así nunha ferramenta para obter máis recursos económicos, non soamente a través das expectativas de 
crecemento futuro, senón simplemente da actividade construtiva asociada e da posibilidade de atraer poboación (Buzbee 1999).

Non obstante, os municipios galegos foron bastante reticentes a obter recursos da actividade urbanística (Álvarez Corbacho 2012). O que fixeron foi ofertar máis solo para tratar de capturar unha demanda que cada vez é máis escasa debido ao declive demográfico.

Outra característica dos municipios galegos é a baixa competencia política existente e o dominio predominante dun partido conservador, que posúe máis da metade dos escanos a nivel local. Existen evidencias na literatura académica de que os gobernos locais, con pouca competencia electoral e con partidos conservadores, tenden a ser máis laxos en relación cos expansión do solo urbano (Kahn 2011, Gerber e Phillips 2003). En España demostrouse que, para municipios de similares características, os gobernos locais progresistas desenvolvían un $65 \%$ menos de solo que os máis conservadores (Solé-Ollé / Viladecans-Marsal 2013).

A transición urbana, a pesar de ser un fenómeno global debido a que a terra urbana incrementou a porcentaxe coa que contribúe á riqueza nacional dos países, pode ter máis repercusións ou menos segundo a incidencia dos factores comentados arriba. No caso de Galicia, rexión periférica en termos socioeconómicos, e polo tanto institucionais, con respecto a España e Europa, agrávase aínda máis.

\section{CONCLUSIÓNS}

Como explicabamos ao inicio, a transición urbana entendida como cambio demográfico rural-urbano é un fenómeno global. Non obstante, os escenarios que deixa tras de si son diferentes en cada país ou rexión. No caso galego, a transición urbana pode ter características de sobreurbanización, entendida a urbanización non só como a superficie construída senón como a clasificación da 
terra para fins urbanos, edifíquese ou non finalmente. A outra cara da moeda que deixa a transición urbana é un abandono progresivo da superficie cultivable en Galicia ao mesmo tempo que, nalgunhas zonas cada vez máis especializadas, se realiza agricultura moi intensiva. Ademais, este abandono e intensificación da agricultura van acompañados dun aumento da superficie forestal, unha dinámica territorial global que se adoita denominar co concepto de transición forestal. Podemos entón dicir que a transición urbana tivo un grande impacto en Galicia. Dá a impresión de que Galicia ten dificultades para poder controlar os efectos que estas dinámicas territoriais están causando no territorio e ser capaz de promover un desenvolvemento urbano racional e sostible, acompañado da protección dun recurso tan escaso como é a terra con capacidade produtiva. Gran parte das razóns que dificultan que os diferentes niveis de goberno poidan controlar o proceso urbanizador son tamén válidas para comprender as dificultades que temos para xestionar o escenario que nos deixou a transición urbana, como o abandono da agricultura e o incremento da superficie forestal.

O escenario actual en Galicia é diverso e caótico. En moitas áreas rurais o abandono dos usos leva incluso ao abandono por completo da propiedade, mentres que nas áreas urbanas o propietario exerce cada vez máis posicións de monopolio. A falta de integración e xerarquización das políticas territoriais e a reforma e mellora da coordinación dos diferentes niveis administrativos para superar a ineficaz aplicación do marco legal son tarefas aínda pendentes en materia territorial en Galicia. Disciplinas como a xestión territorial poñen á disposición instrumentos metodolóxicos e conceptuais que permitirían abordar boa parte destas eivas. 


\section{REFERENCIAS BIBLIOGRÁFICAS}

Alonso, W. (1964): Location and land use, Cambridge, Harvard University Press.

Álvarez Corbacho, X. (2012): III Foro de Economía Galega, Santiago de Compostela.

BRENNER, N. / C. SCHMid (2014): «The 'urban age' in question», International Journal of Urban and Regional Research, 38:3, 731-755.

BUZBEE, W. E. (1999): «Urban sprawl, federalism, and the problem of institutional complexity», Fordham Law Review, 68, 57.

DeSA, U. N. (2014): World urbanization prospects. The 2011 revision, Nova York, Population Division, Department of Economic and Social Affairs, United Nations Secretariat.

Díaz-Fierros Viqueira, F. / F. Gil Sotres (1984): Capacidad productiva de los suelos de Galicia, Santiago de Compostela, Universidade de Santiago de Compostela.

DuBOIS, O. (2011): The state of the world's land and water resources for food and agriculture: managing systems at risk, Reino Unido, Earthscan.

ENVIRONMENTAL EUROPEAN AGENCY (2016): Urban sprawl in Europe (https://www.eea.europa. eu/publications/urban-sprawl-in-europe) [última consulta: novembro, 2018].

Fujita, M. / P. Krugman / A. Venables (1999): The Spatial Economy. Cities, Regions, and International Trade, Cambddge, MIT Press.

Gerber, E. R. / J. H. PhilLips (2003): «Development ballot measures, interest group endorsements, and the political geography of growth preferences», American Journal of Political Science, 47:4, 625-639.

HARVEY, D. (1989): «From managerialism to entrepreneurialism: the transformation in urban governance in late capitalism», Geografiska Annaler: Series B, Human Geography, 71:1, 3-17.

Hita, F. C. / R. E. Orayen / P. P. Arzoz (2011): «Municipal indebtedness in Spain revisited: the impact of borrowing limits and urban development», en XVIII Encuentro de Economía Pública.

KAHN, M. E. (2011): «Do liberal cities limit new housing development? Evidence from California», Journal of Urban Economics, 69:2, 223-228.

Maldonado, J. S. / J. S. PANDiello (2007): «Hacienda local y urbanismo: ¿es tan grave como lo pintan?», Revista Económica de Castilla-La Mancha, 11, 245-264.

RomÁn, J. B. / J. I. G. Rebaque (2017): «La actividad urbanística y la financiación de los ayuntamientos. El impacto de los ingresos urbanísticos en los presupuestos municipales (2005-2013)», Ciudades, 19, 191-216.

Seto, K. C. / M. Fragkias / B. GÜneralp / M. K. Reilly (2011): «A meta-analysis of global urban land expansion", PLOS ONE, 6:8, 1-9.

SolÉ-Ollé, A. / E. ViladeCAns-Marsal (2013): «Do political parties matter for local land use policies?», Journal of Urban Economics, 78, 42-56.

Sovani, N. V. (1964): "The analysis of "over-urbanization"», Economic Development and Cultural Change, $12: 2,113-122$.

STIGLiTZ, J. E. (2015): «New theoretical perspectives on the distribution of income and wealth among individuals: Part IV: Land and Credit», National Bureau of Economic Research, 1-36.

Triantakonstantis, D. / D. Stathakis (2015): «Examining urban sprawl in Europe using spatial metrics», Geocarto International, 30:10, 1092-1112. 